\title{
How to Prepare Biological Samples and Live Tissues for Scanning Electron Microscopy (SEM)
}

\author{
Abolfazl Mehdizadeh Kashi ${ }^{1,2}$, Kobra Tahermanesh ${ }^{1,2 \bowtie}$, Shahla Chaichian ${ }^{1,3}$, Mohammad Taghi Joghataei ${ }^{4,5}$, Fateme \\ Moradi $^{4,5}$, Seyed Mohammad Tavangar ${ }^{6}$, Ashraf Sadat Mousavi Najafabadi ${ }^{2}$, Nasrin Lotfibakhshaiesh ${ }^{7}$, Shahram Pour \\ Beyranvand $^{8}$, Abbas Fazel Anvari-Yazdi ${ }^{9}$, Seyedeh Mehr Abed ${ }^{10}$
}

\footnotetext{
'Endometriosis Research Center, Hazrat-e Rasool-e-Akram Hospital, Iran University of Medical Science (IUMS), Tehran, IR-Iran. ${ }^{2}$ Minimally Invasive Surgery Research Center, Hazrat-e Rasool-e Akram Hospital, Iran University of Medical Science (IUMS), Tehran, IR-Iran.

${ }^{3}$ Department of Obstetrics and Gynecology, Minimally Invasive Technology Research Center of Tehran Medical Sciences Branch (TMSB), Islamic Azad University (IAU), Tehran, IR-Iran.

${ }^{4}$ Department of Cellular and Molecular Research Center, Faculty of Medicine, Iran University of Medical Sciences (IUMS), Tehran, IR-Iran.

${ }^{5}$ Department of Anatomy, Faculty of Medicine, Iran University of Medical Sciences (IUMS), Tehran, IR-Iran. ${ }^{6}$ Department of Pathology, Shariati Hospital, Tehran University of Medical Sciences (TUMS), Tehran, IR-Iran.

${ }^{7}$ Tissue Engineering Department, School of Advanced Technologies in Medicine, Tehran University of Medical Sciences (TUMS), Tehran, IR-Iran.

${ }^{8}$ Department of Anatomy, Faculty of Medical Sciences, Tarbiat Modares University, Tehran, IR-Iran.

${ }^{9}$ Division of Biomedical Engineering, Materials and Biomaterials Research Center (MBMRC), Tehran, IR-Iran.

${ }^{10}$ School of Medical Science, Yasuj University of Medical Sciences (YUMS), Yasuj, IR-Iran.
}

\begin{abstract}
In this article we review the application and procedures involved in scanning electron microscope (SEM) to observe biological and live tissues through using SEM at high resolution. We discuss practical methods for optimizing tissue preservation to achieve the two principal goals of biological specimen preparation: (a) preserving biological structures as close to their living configuration as possible, and (b) rendering them visible with the desired imaging method. We also review and discuss the relative merits of different fixing (chemical fixation and cryofixation), drying (air-drying, critical point-drying, freeze-drying and chemical-drying) and coating procedures of biological specimens with metals to facilitate visualization in the SEM. [GMJ. 2014;3(2):63-80]
\end{abstract}

Keywords: Scanning Electron Microscopy (SEM); Biological Samples, Live Tissues, Sample Preparation

\section{Introduction}

$\mathrm{T}$ oday, the Scanning Electron Microscope (hereinafter abbreviated to SEM) is utilized not only in materials, chemical and physic sciences, but also in diverse fields such as medical sciences and biology. The high spatial resolution of an SEM makes it one of the most versatile and powerful instruments

\section{GMJ}

2013 Galen Medical Journal

Fax: +98 7312227091

PO Box 7461686688

Email:info@gmj.ir available for the examination, analysis a wide range of the microstructural characteristics of specimens at the nanometer to micrometer length scale. SEM uses a focused electron probe to extract structural and chemical information point-by-point from a region of interest in the sample.

Biological materials are living tissues, and they are composed primarily of light elements

\footnotetext{
Correspondence to:

Kobra Tahermanesh,MD, Minimally Invasive Surgery,

Endometriosis Research Center, Hazrat-e Rasool-e

Akram Hospital, Iran University of Medical Science,

Tehran, IR-Iran.

Telephone Number: +98(0)21-665-09283

Email Address :dr.floratary@gmail.com
} 
closed to $99 \%$ of chemical composition $\mathrm{Z}=1$ 20 and include the major elements $(\mathrm{H}, \mathrm{C}, \mathrm{N}$, $\mathrm{O})$ and minor elements ( $\mathrm{Na}, \mathrm{Mg}, \mathrm{Si}, \mathrm{P}, \mathrm{S} ., \mathrm{Cl}$, $\mathrm{K}$, and $\mathrm{Ca}$ ). The remaining $1 \%$ is made up primarily of $Z=24-30$ and includes the trace elements $\mathrm{Cr}, \mathrm{Co}, \mathrm{Cu}, \mathrm{Fe}, \mathrm{Mn}, \mathrm{Zn}$, and I, which are important in various metalloenzymes and coenzymes [1]. Water is an essential component of living biological samples, together with complex organic macromolecules such as proteins, lipids and carbohydrates. The various elements that make up the cell are: 59\% Hydrogen (H), 24\% Oxygen (O), 11\% Carbon (C), 4\% Nitrogen (N), 2\% Others - Phosphorus (P), Sulfur (S) and etc. Table 1 shows a list of elements, symbols, atomic weights and their biological roles in body [2].

One of the most challenges in interpreting SEM images of biological specimens is to be able to distinguish between those features that reflect the native structure and those that are artificially created during processing. Otherwise, even the most sophisticated and high resolution methods may yield meaningless images. Such artificially induced structures are referred to as artifacts. The problem of distinguishing real structures from artifacts is compounded by the fact that most microscopic methods from images not of biological structures directly, but stains, dyes, or coatings that are added to the specimen to render the parts of interest visible, but which themselves are artifacts [4].

Besides providing useful information, the electron beam used in an SEM can cause temporary or permanent change in the surface or bulk structure of a specimen. One way of categorizing this damage is in terms of the type of electron scattering that gives rise to it (Figure. 1) [5]. Biological materials are poor or non-conductors of thermal and electrical and very susceptible to radiation damage.

To observe the microstructure of living tissues under SEM, some considerations are required. Conventional SEM's operate at very high vacuums to avoid gas molecules interfering with both the primary electron beam and the secondary or backscattered electrons emitted from the sample. This means that everything going into the SEM must be completely dry

Table 1. Essential Elements for Construction of Diifrent Biological Systems in Body [3].

\begin{tabular}{|c|c|c|c|c|}
\hline Element & Symbol & $\begin{array}{c}\text { Atomic } \\
\text { Weight }(Z) \\
\end{array}$ & $\begin{array}{l}\text { Percentage in } \\
\text { Body }\end{array}$ & Biological Role \\
\hline Oxygen & $\mathrm{O}$ & 16.0 & 65 & $\begin{array}{l}\text { Respiration; part of water; and in nearly all organic } \\
\text { molecules }\end{array}$ \\
\hline Carbon & $\mathrm{C}$ & 12.0 & 18.5 & Constituent (backbone) of organic molecules \\
\hline Hydrogen & $\mathrm{H}$ & 1.0 & 9.5 & Part of water and all organic molecules \\
\hline Nitrogen & $\mathrm{N}$ & 14.0 & 3.2 & Constituent of all proteins and nucleic acids. \\
\hline Calcium & $\mathrm{Ca}$ & 40.1 & 1.5 & Bone; muscle contraction, second messenger \\
\hline Phosphorus & $\mathrm{P}$ & 31.0 & 1 & $\begin{array}{l}\text { Constituent of DNA and RNA backbones; high energy } \\
\text { bond in ATP }\end{array}$ \\
\hline Potassium & K & 39.1 & 0.4 & Generation of nerve impulses \\
\hline Sulfur & $\mathrm{S}$ & 32.1 & 0.3 & $\begin{array}{l}\text { Constituent of most proteins. Important in protein } \\
\text { structure: Sulfide bonds are strong }\end{array}$ \\
\hline Sodium & $\mathrm{Na}$ & 23.0 & 0.2 & Part of Salt; nerve conduction \\
\hline Chlorine & $\mathrm{Cl}$ & 35.5 & 0.2 & Digestion and photosynthesis \\
\hline Iron & $\mathrm{Fe}$ & 55.8 & Trace $^{*}$ & Essential component of hemoglobin in the blood \\
\hline Copper & $\mathrm{Cu}$ & 63.5 & Trace & Part of Oxygen - carrying pigment of mollusk blood \\
\hline Zinc & $\mathrm{Zn}$ & 65.4 & Trace & Essential to alcohol oxidizing enzyme \\
\hline Iodine & I & 126.9 & Trace & Part of thyroxin (a hormone) \\
\hline
\end{tabular}

* Less than $0.1 \%$ 
and free of any organic contaminants that may potentially outgas in a high vacuum environment. This poses a problem when dealing with biological specimens which are largely composed of water, necessitating additional preparatory steps to ensure the native structure of the organism is retained. The steps necessary depend on sample type and the purpose of the study. Some types of biological tissues or specimens will require less stringent processing to preserve their structure. Other more delicate types of samples will take time and care to prepare to avoid the introduction of drying artifacts, such as shrinkage and collapse.

The results of morphometric studies on tissue sections may be markedly influenced by specimen preparation procedures, such as fixation, dehydration, embedding, and, indeed, by the type of tissue [6, 7]. Many biological samples are commonly prepared through fixation and dehydration and coated after drying with metal such as gold, platinum or palladium to make their surfaces electrically conductive for SEM analysis. Diagram 1 and Figure 3 outline the major steps involved in preparing whole biological samples for SEM observation respectively. The nature and combination of steps used will vary depending on the nature of the sample, the type of microscopic method, and the specific scientific goals. For other reviews of the various procedures for preparing biological specimens for SEM, please consult references [8-10]. Briefly, each level described here:

\subsection{Sample collection}

The sample collection from tissues is effective on final results. It is important to try to collect a representative sample from living tissues. In biological sample collection, dissecting of tissues must be done carefully. For example, at the time of dissection of a small piece of tissues for diagnostic aim the surgeon must be careful in grasping and dissection.

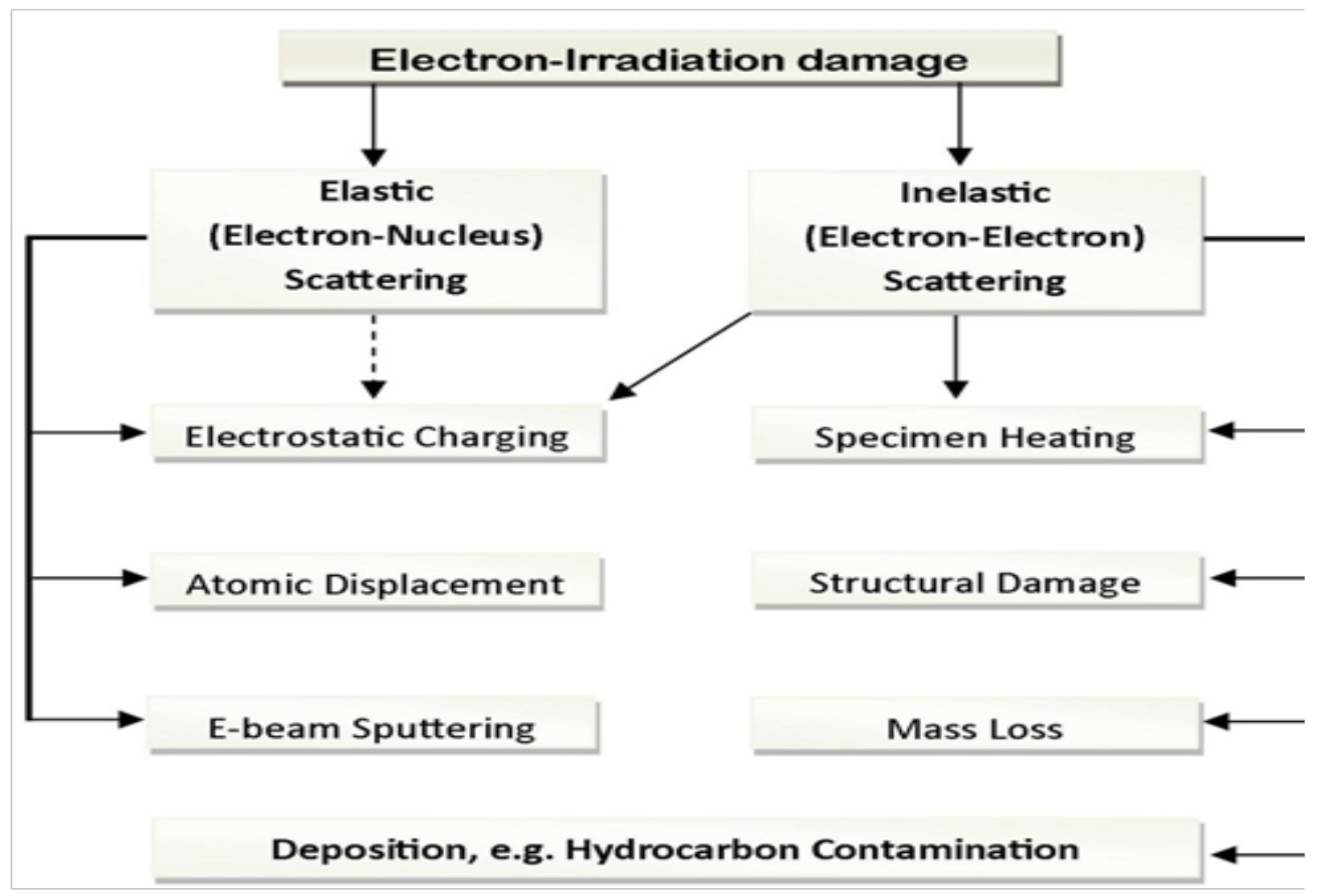

Figure 1. Classification of Radiation Damage According to the Type of Electron. Reprinted with Permission from Reference: [5]. 


\subsection{Fixation}

The first and most important step after sample selection for the study of living tissues is their rapid and suitable fixation method. Before cellular decomposition begins immediately after the death of an organism, the assistant must fix the cells to prevent alterations in their structure through decomposition. Routine fixation involves the chemical cross-linking of proteins (to prevent enzyme action and digestion) and the removal of water to further denature the proteins of the cell. A fixation composition stops cellular processes and aim to preserve the specimen as close as possible to its natural state. Characteristics of a good fixative are: permeates cells readily and acts quickly, are irreversible and does not cause fixation artifacts.

\subsubsection{Traditional chemical fixation}

Before beginning this part, author want to recommend two texts by Hayat $[11,12]$ which are invaluable sources that contain information concerning all aspects of biological specimens preparation in much greater depth than can provided in this article. The text by Glauert and Lewis [13] also gives in-depth attention to all aspects of fixation and embedment of biological samples. In this part, the techniques will be discussed primarily in regard to preparing specimens for SEM as well. The primary goal of fixation is to stabilize the structure of the sample so that it can withstand both subsequent processing steps and examination under the SEM. Fixation methods can be divided into two basic types: chemical and physical (Table 2). Chemical fixation is more commonly used, but the use of physical methods, primarily freezing, has been growing [4].

\subsubsection{Chemical fixation}

In discussing the effects of chemical fixatives on samples, several factors need to be considered. These include the nature of fixative itself, the composition of the vehicle in which the fixative is dissolved, and the physical conditions under fixation is carried out.

\subsubsection{The fixative}

Chemical fixatives fall into two board categories: those that fix by denaturing and coagu- lating biological macromolecules, and those that fix by covalently crosslinking macromolecules. Denaturing fixatives such as acetone, ethanol, and methanol preserve ultrastructure very poorly and are useful almost exclusively for light microscopy (LM). In contrast, crosslinking fixatives, by introducing intermolecular and, sometimes, intramolecular crosslinks between macromolecules, provide excellent ultra-structural preservation. The most widely used crosslinking fixatives are FA for LM, and GA and OT for SEM [4, 14].

\subsubsection{Formaldehyde}

Formaldehyde (FA) with the formula $(\mathrm{CH} 2 \mathrm{O})$ is a mono-aldehyde that reacts with amine groups to form crosslinks between adjacent macromolecules, primarily proteins [15]. Because the crosslinking is based on the formation of a methylene bridge between two FA molecules, the crosslinks are short and can be reversed by hydrolysis. FA is a very useful for LM [16]. The utility of FA for high resolution works limited. For SEM, FA fixation should be followed by additional fixation in GA. FA should be made fresh from paraformaldehyde powder. Commercially available FA solution (formalin) contain methanol as preservative and should be avoided. To prepare FA as $20 \%$ aqueous stock solution by adding the powder fixative to distilled water and then heated to $95-99^{\circ} \mathrm{C}$ ) with continuous striring, and then adding $1.0 \mathrm{M} \mathrm{NaOH}$ drop by drop until the soloution becomes clear. After adjusting the $\mathrm{pH}$ with $\mathrm{HCL}$ and adjusting the final volume with water, store it in the dark at $4^{\circ} \mathrm{C}$ for at least 2 months [4]. At room temperature $\left(25^{\circ} \mathrm{C}\right), \mathrm{FA}$ bound to tissue sections increased with time until equilibrium was reached. Since the tissue sections were extremely thin $(16 \mu \mathrm{m})$, penetration was not considered a factor in kinetics of the reaction. At $37^{\circ} \mathrm{C}$, the reaction of FA is

Table 2. Common Biological Fixatives [4].

\begin{tabular}{ll}
\hline & Acetone \\
& Alcohols \\
Chemical Methods & Formaldehyde (FA) \\
& Glutaraldehyde (GA) \\
& Osmium tetroxide (OT) \\
& Protein crosslinking reagents \\
\hline \multirow{2}{*}{ Physical Methods } & Heating \\
& Freezing \\
\hline
\end{tabular}


considerably faster and equilibrium is reached after $18 \mathrm{hr}$ or less. A major concern in fixation by FA, or with any fixative, is the amount of distortion produced by fixation. The useful term applied to fixation distortion is shrinkage [15].

\subsubsection{Glutaraldehyde}

Glutaraldehyde (GA) is a di-aldehyde which can react simultaneously with two amine to form both inter and intra-molecular crosslinks, primarily with proteins $[4,11]$. GA can also react with itself to form long, branched, multivalent crosslinking molecules that can span the gap between nearby proteins and introduce multiple and essentially irreversible crosslinks that convert the cytoplasm of all cell into a macromolecular gel. GA preserves fine structure at least down to the level of macromolecular resolution and renders samples highly resistant to the various processing steps required to prepare them for SEM, making it the fixative of choice for almost all biological SEM. Although it does not fix lipids, GA stabilizes biological membranes sufficiently well that they resist extraction with detergent and GA-fixed cells remain osmotically active for some time after fixation [4, 17-20].

\subsubsection{Osmium tetroxide}

Osmium tetroxide (OT) is a popular fixative foe SEM, because it crosslinks most lipids and renders them resistant to extraction by organic solvents used to dehydrate samples prior to drying them [21]. Although OT preserves biological membranes, it also causes them to become osmotically inactive and permeable to water. In sections of cells examined by transmission electron microscopy (TEM), osmium also stains biological membranes by generating the two black pararell lines that mark the location of the lipid bilayer. However, because OT can damage proteins and other components [21,22], it is better that samples not to be osmicated unless there is a specific reason for using so [4].

\subsubsection{Protein crosslinking reagents}

Biofunctional protein crosslinking reagents form inter and intramolecular crosslinks between proteins, thereby functioning similarly to GA, except that they do not self-associate to form multivalent reagents [23-26]. The distance across which they can form cross- links is determined by length of molecule between its two reactive ends. A large variety of bi-functional protein crosslinking reagents is available commercially, primarily from Pierce (Rockford, IL), but few have been tested as fixatives for microscopy [4].

\subsubsection{Vapor fixation}

Fixation of biological samples for SEM, in general, utilizes the same principles and materials as described above. But some samples are so easily damaged that immersion in a fluid is not possible. This is particularly the case for fungal hyphae and their fruiting bodies (conidia) that separate from the parent plant upon touching. Vapor fixation uses a drop of fixative placed near the sample, in a sealed container. In the case of excised infected leaf material, $4 \%$ OT made up in water, fixes the sample in about 1 hour. The sample turns black when fixed, which helps assess progress. Once fixed, the sample can be frozen by placing it on a metal block cooled with liquid nitrogen, and then freeze dried. OT post fixation can usually be omitted, though samples that have "charging problems" leading to image distortion can frequently benefit from osmication [27].

\subsubsection{Physical fixation}

As mentioned before in table 2, two alternatives to chemicals for fixing boplogical material are heating and freezing. Both have their uses for LM, but freezing (cryofixation) is the approach that offers the best alternative to chemical fixation for preserving biological fine structure for high resolution microscopy.

\subsubsection{Cryofixation}

The rapid freezing of biological specimens has the potential of stopping all molecular motion almost instantaneously and literally freezing fine structure in place. There are a variety of methods available to freeze biological material. These methods will not be reviewed in detail here. For further more information author recommended to see references $[4,28$ 31]. Ice crystals damage is the major obstacle to good cryofixation. Ice crystal growth is affected by the speed of freezing, which in turn is determined by the heat transfer rate of the coolant and the size of the specimen. To avoid ultrastructural damage to the specimen caused 
by growth of large ice crystals, rapid freezing is essential. True verification (i.e., formation of amorphous, non-crystaline ice) can be achived only by cooling rates of greater than $2 \times 10^{5}{ }^{\circ} \mathrm{C} / \mathrm{s}$ over the critical range of 20 to $-100^{\circ} \mathrm{C}$, i.e., cooling over this range in a fraction of millisecond. Rates of this magnitude can be attained in very thin $(<3 \mu \mathrm{m})$ tissues of suspended liquid that are plunged rapidly into liquid nitrogen-cooled liquid propane or ethane [32]. Liquid propane, with a heat transfer rate of $3900^{\circ} \mathrm{C} / \mathrm{s}$, is the most effective of the various coolants that have been tested. It is also inexpensive and easy to use. [33]. To achieve ice crystal free freezing, cells must be frozen at a rate over $1000^{\circ} \mathrm{C} / \mathrm{s}$. Very thin samples such as individual cells can be frozen this rapidly, but the slower rate of freezing for thicker samples such as tissues limits the ice crystal free zone to a layer of only a few micrometers located closest to the freezing medium or surface $[29,30]$.

\subsubsection{Purpose; Killing versus Fixing}

When preparing samples, one of the first concepts to consider is the difference between killing and fixing. Most of the time, the term fixing is used to include both processes, which sometimes leads us to forget that they are not one and the same thing. Most primary fixatives used today are aldehyde group fixatives, and it is well documented that cells can have significant time periods during which they can respond to fixative solutions before death
(Table 3). Slime mold amoebae grown to confluence on an agar surface can be seen round up and develop intercellular spaces during the first 30s after a GA mixture is poured onto them. If, instead, the petri dish contain the cells is first inverted over a drop of $1 \%$ OT for $3 \mathrm{~min}$, the addition of GA causes no obvious morphological change in cells. Thus, the highly volatile and toxic OT vapor kills the cells, and the later addition of GA fixes the cells. It is important not to forget that these processes are not the same thing when evaluating the success or failure of your particular fixation regimen [27].

In summary, aldehyde fixation is frequently adequate. Two main fixtures for this aim are GA and FA. GA quickly and irreversibly cross-links proteins via their amino groups. However, it does penetrate tissue quite slowly and is therefore often used in combination with FA. FA reversibly cross-links proteins, but is a small molecule and penetrates tissue quite quickly [35]. Balancing the osmolarity of the fixative solution with the internal osmolarity of the cells or tissues being fixed is critical to maintaining normal morphology and fine structure [36]. If the osmolarity of the fixative is lower than cells, they will take up water and swell, whereas if it is higher, the cells will lose water and shrink, osmotic stress can also cause the rupture of internal membrane-bound compartments and the redistribution of intercellular components. GA, PA

Table 3. Rates of Fixation [34].

1. Chemical fixation

A. $3 \%$ Glutaraldehyde / 3\% Acrolein: Pyrsoneympha axoneme moves for 2 seconds.

B. $3 \%$ Glutaraldehyde: chicken embryo fibroblast cytoplasmic inclusions move for 30-45 seconds.

C. Tomato petiolar hair cell cytoplasmic streaming continues for:

1) 15 min with $0.5-5.3 \%$ Glutaraldehyde

2) 9 min with $5 \%$ acrolein

3) 6 min with $2 \%$ Glutaraldehyde $+5 \%$ acrolein

4) 15 min with $2 \%$ Glutaraldehyde $+1 \%$ osmium

2. Cryofixation: Movement cases in $10 \mathrm{msec}$ 
and OT cross the membrane freely and do not contribute osmotic pressure to cells and tissues $[4,18,37]$.

Many biological structures are sensitive to temperature. Temperature of solution at the beginning of fixation recommended keeping at the same temperature at which the sample was kept while alive. After the sample is well fixed, the temperature can be lowered to room temperature (RT), for convenience, or $4^{\circ} \mathrm{C}$ for longer storage. Also samples can be stored in a refrigerator to inhibit the growth of any contaminants that may occur over time. Other reasons for fixing at colder temperatures $(0-$ $4^{\circ} \mathrm{C}$ ) include: to reduce the lateral mobility of membrane proteins, to slow the diffusion of intercellular molecules, and to slow the rate of fixation, which must be done with OT or mixtures of OT and GA [4].

The time required to fix cells and tissues adequately is largely depend on the speed with which the fixative diffuses into the specimen and the rate at which fixative reacts with the components of specimen. The minimum time required for fixation will depend on the type and size of the sample. For example, cells in culture appear to be fixed almost instantaneously, although $15-30 \mathrm{~min}$ at $37^{\circ} \mathrm{C}$ is probably a safe time to ensure adequate fixation. Bacterial cells may only need 30 minutes whilst a thicker piece of tissue from an animal or plant will need to be left in fixative overnight or even for a couple of days (approx. 8 hours) to ensure complete infiltration. Almost all the specimens can be stored in GA in the cold for extended periods of time, if necessary. But prolonged exposure to OT can be very destructive and should be avoided, and the reversible nature of FA crosslinking makes prolonged storage in that fixation unwise [4]. At last, all fixatives should be buffered to maintain $\mathrm{pH}$ at around the physiologic $\mathrm{pH}$ of the sample, typically 7.2-7.4 for mammalian tissues [4].

\subsection{Dehydration}

Conventional SEM demands that water and organic fluids either must be removed from samples or immobilized before they are examined and analyzed. Strictly speaking, the term "dehydration" is used to describe the removal of water. Because biological materials are predominately composed of water, dehydration is potentially a very disruptive and artifact producing process due to:

1. Extraction of molecules by the dehydrating solvent,

2. Precipitation of molecules due to loss of water,

3. Shrinkage of the sample due to loss of water, and

4. Crushing of sample by the solvent-air interface.

Shrinkage is an unavoidable artifact of dehydration, because loss of the water solvent that surrounds the macromolecules causes them become more tightly packed together $[4,38$, 39]. Therefore, samples should be dehydrated so as to allow them to shrink gradually and not collapse due to rapid loss of water [4].

For this aim many different methods such as air drying and chemical dehydration are introduced. The most commonly used dehydrating agents are methanol, ethanol and acetone.

Ethanol and acetone are common dehydrating fluids to preserve the original structure of biological samples like peritoneal tissue. The dehydration process is accomplished by passing the tissue through a series of increasing alcohol concentrations. The blocks of tissue are transferred sequentially to $30 \%, 50 \%, 70 \%$, $80 \%, 90 \%, 95 \%$, and $100 \%$ alcohol [40-43]. The blocks are then placed in a second $100 \%$ ethanol solution to ensure that all water is removed. Note that ethanol is hygroscopic and absorbs water vapor from the air. Absolute ethanol is only absolute if steps are taken to ensure that no water has been absorbed. For this reason, usually begin dehydration in 15$30 \%$ solvent in water, and increase the concentration of solvent to $100 \%$ in steps of 15 $20 \%$ [4]. It is important to distinguish between dehydration and drying. Tissues should never be allowed to air dry. Dehydration involves slow substitution of the water in the tissue with an organic solvent. Dehydration must be conducted relatively rapidly in order to prevent excessive extraction of alcohol and acetone-soluble compounds, but slow enough to prevent plasmolysis. Extraction of specimen components is difficult to control. Low mo- 
lecular weight carbohydrates are particularly susceptible, since carbohydrates are usually poorly cross-linked if at all following fixation. Proteins tend to be cross-linked by GA during primary fixation and the lipids by OT during secondary fixation. The carbohydrates are essentially unfixed. Linked to the problem of extraction is that of shrinkage. Both problems are most serious at low concentrations in the dehydration series. In general, rapid dehydration is best for these reasons. By $70 \%$ alcohol, the tissue no longer shrinks as much, but does begin to harden. In fact, extended periods of dehydration in higher concentrations of alcohol may make the tissue quite brittle. If a stopping point is needed, most histologists choose $70 \%$ to $100 \%$ alcohol as a good place to stop for the evening. If there is evidence of plasmolysis, perhaps additional dehydration steps (and/or longer changes) may be required. Cell membranes sometimes retain some osmotic activity after short periods of fixation. Longer periods of fixation in GA can reduce osmotic sensitivity as well. Membranes are essentially insensitive to osmotic changes after 48 hours of fixation in GA. Poor fixations will aggravate problems with dehydration. Dehydration at refrigerator temperatures slows the process down a bit and tends to lend some rigidity to the tissue. It may also reduce plasmolysis slightly. In living tissues are the most sensitive to poor dehydration, and therefore, refrigerated dehydration is preferred for these tissues. When changing solutions, make sure that the specimen does not dry out. Therefore, most workers do not purport the bottom of the vial, dry between changes, but leave a little liquid to keep the specimens dry. On the basis of relative volumes, this remaining solution is inconsequential. Generally, the following dehydration processes recommended for living tissues:

1. Rinse your samples with fresh buffer (no fixative added) in the fume hood - repeat three times.

2. Replace buffer solution with the lowest concentration ethanol solution in your dehydration series - e.g. 50\%, and leave for 15-20 minutes.

3. Continue with this process until your samples are in $100 \%$ ethanol, then repeat the $100 \%$ ethanol step.

4. Samples are now dehydrated and ready for drying.

\subsection{Drying}

Many biological samples contain fluid, much of which is water. Evaporating fluid can also negatively affect the machine operation. It is therefore best to ensure the sample is dry before inserting it in the SEM sample chamber. Once the dehydration series is complete, the solvent itself must be removed from the tissue without introducing surface tension/drying artifacts into the sample. This is achieved through the use of a transitional fluid, most commonly critical point drying (CPD), freeze-drying (FD) or liquid $\mathrm{Co}_{2}$ or a series of solvents, e.g., hexamethyldisilazane (HMDS), Freon 113, tetramethylsilane (TMS), and PELDRI II, are sometimes employed for air drying; because they reduce high surface tension forces that cause collapse and shrinking of cells and their surface features [44-55].

Artifacts such as shrinkage and collapse of surface structures due to the effects of surface tension can be a problem if biological samples are air dried following dehydration. Considerable forces are created in small cavities when a liquid/gas interface is present and as the sample dries this interface travels through the tissues, collapsing cavities as it goes. This phenomenon can even lead to complete collapse of hollow specimens. Any deformation that occurs may then be mistakenly identified as a native feature of the sample, or as an effect of a particular treatment applied.

\subsubsection{Air Drying}

A major problem arises as water is removed from specimens by drying in air. As the water/ air interface passes initially from the surface and then through the bulk of the specimen, the surface tension forces associated with the interface can rise to as high as $2000 \mathrm{ib} /$ in $2(13.8 \mathrm{MPa})$, which can result in up to $45 \%$ shrinkage during the final phases of air drying [56]. These forces become increasingly larger as the structures being dried become smaller. This dramatic increase in surface tension severely distorts the structural integrity of soft 
specimens in additional to problems with specimens that contain dissolved inorganic and organic solutes $[27,57]$.

\subsubsection{Critical Point Drying (CPD)}

Critical point drying (CPD) is an established method of dehydrating biological tissue prior to examination in the Scanning Electron Microscope. The technique was first introduced commercially for SEM specimen preparation by Polaron Ltd in 1970. Traditionally biological samples have been processed via CPD to avoid shrinkage effect $[58,59]$. CPD is based on the principle that under certain temperature and pressure conditions, a fluid and its overlaying vapor will become indistinguishable (the critical point) (Figure. 2). At this point, the surface tension on a specimen originally in the fluid phase will be zero. For biological samples the main concern is to remove water, however, the critical point for water of $+374^{\circ} \mathrm{C}$ and 3212 PSI is inconvenient, and would cause heat damage to the specimen. To avoid this harsh conditions, a sample that has been dehydrated to the point of $100 \%$ ethanol (as outlined in the procedure above), is then placed in the chamber of a CPD apparatus with enough $100 \%$ ethanol to completely cover it. Then the chamber purged repeatedly with liquid $\mathrm{Co}_{2}$ until all the ethanol has been replaced with $\mathrm{Co}_{2}$. The chamber is then sealed and cooled until the critical point for $\mathrm{Co}_{2}$ is reached $\left[31^{\circ} \mathrm{C}\right.$ and $\left.1072 \mathrm{ib} / \mathrm{in}^{2}(7.4 \mathrm{MPa})\right]$, as valves are opened to let liquid $\mathrm{Co}_{2}$ in and vent ethanol out, until liquid $\mathrm{Co}_{2}$ has completely replaced the ethanol. The chamber is then sealed again and slowly heated. When the chamber pressure exceeds 1072 PSI and the temperature exceeds $31^{\circ} \mathrm{C}$, a critical point is achieved whereby the liquid and gas phases of $\mathrm{Co}_{2}$ are in equilibrium. If the temperature of the chamber is maintained above the critical temperature $\left(36-38^{\circ} \mathrm{C}\right)$, the chamber can be vented to release $\mathrm{Co}_{2}$ gas without any danger of recondensation into liquid $\mathrm{Co}_{2}$ to produce surface tension on biological specimen. The chamber should be vented slowly, and the temperature gauge must be closely observed. Allowing gas to escape through a small orifice (the venting valve) at high velocity will cause a temperature drop. If the temperature drops below the critical point, specimen surfaces can become rewetted and suffer surface tension damage $[27,60]$. Table 4 shows Temperature-Pressure critical points of some substances.

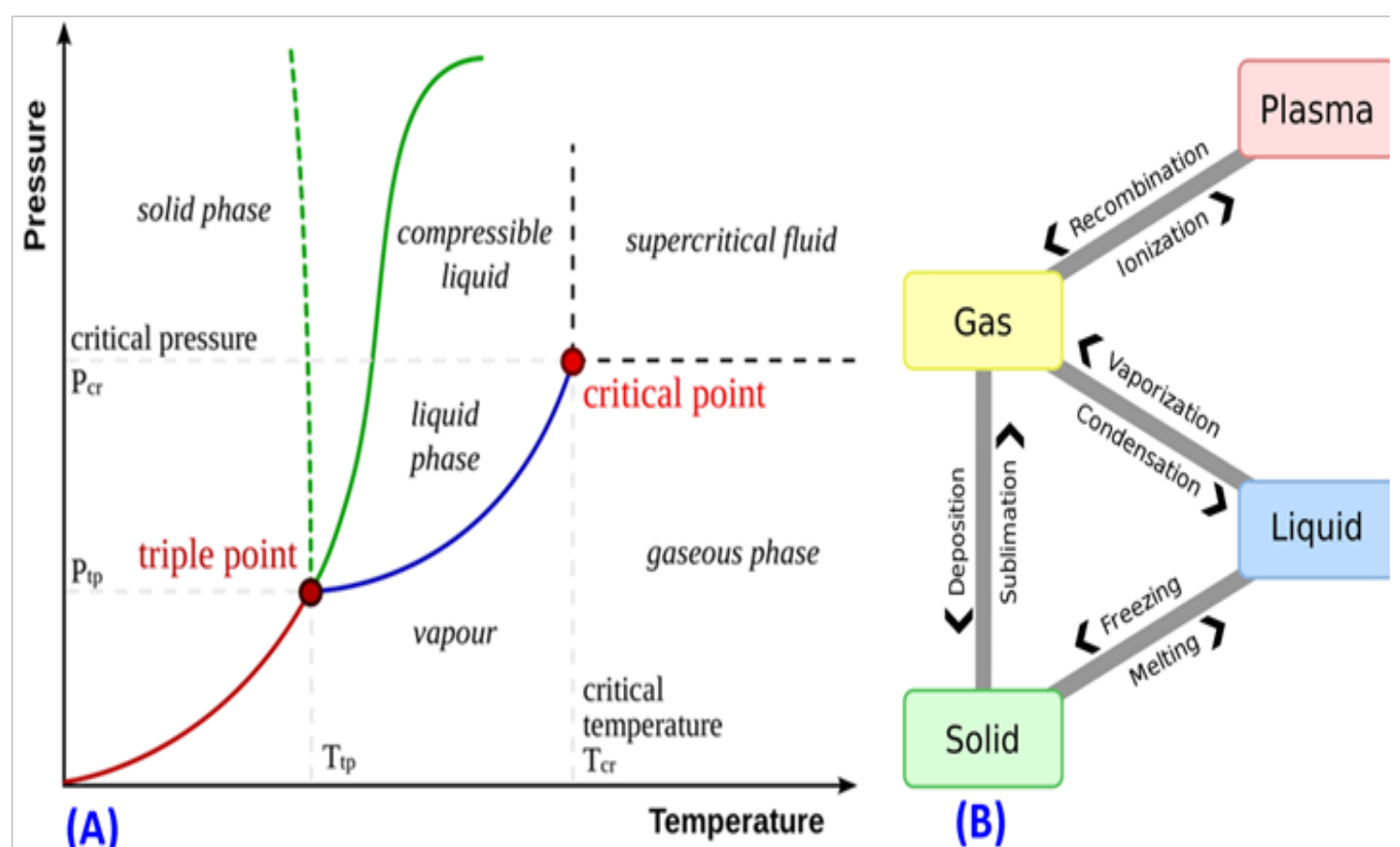

Figure 2. (A) The vapor-liquid critical point in a pressure-temperature phase diagram is at the high-temperature extreme of the liquidgas phase boundary. The dotted green line shows the anomalous behavior of water and $(B)$ the effect of pressure-temperature on enthalpy variation of different states of substances. 
CPD is not a perfect technique. Shrinkage is still observed, resulting in a $1-15 \%$ size reduction in central nervous system materials, $12-13 \%$ shrinkage with embryonic and fetal tissues, and up to $20 \%$ shrinkage for lung, kidney, liver and skin [27, 56, 60,63]. Much of this shrinkage may be due to the fixation and dehydration process itself [27].

\subsubsection{Freeze-Drying}

Freeze-drying (FD) was introduced because, in theory, less shrinkage should occur than with a CPD [64]. Also, FD avoids the perceived danger of the CPD process. The processing schedule is identical through dehydration. Once the specimen is in $100 \%$ ethanol, it may be frozen in liquid nitrogen-cooled FreonTM $12(-158)$ or the sample may simply be cryofixed from its native state. The sample is then placed on a precooled specimen stage held at -40 to -80 , der mild vacuum (1.3310-2 Pa or less) and left for 6-8 hr with most specimens, monolayers need only 1-2 hr, while a 1-3 mm thick specimen might need 3 days. When frost is no longer visible on the cooled stage, indicating that all the fluids have sublimed, the specimen is warmed gradually over a period of $6 \mathrm{hr}$ or so. When the stage and specimen temperatures are slightly above ambient conditions, the chamber may be vented. The specimen should be mounted on a speci- men support, coated and examined as soon as possible.

\subsubsection{Chemical drying agents}

Chemical drying agents have been suggested to eliminate the need for capital investment in CPD or FD as well as the need for facing their complication. The published photographs of materials produced with HMDS and TMS [27, 48, 65-68] shows effective role of both chemical agents as drying solution. This turns to vapor without the crushing surface tension forces of water or even the damage from evaporation caused by ethanol. Samples in solvent (ethanol preferably) can be introduced to HMDS as a 50:50 solution and then changed to $100 \%$ HMDS ( 2 changes). Once in the final change the solution can be drained off till it just covers the sample and left to evaporate in a fume hood. This can take from a few minutes for very small samples to a few days for larger ones. It is a useful alternative to the CPD for large samples that will not fit the CPD chamber. However, not all samples dry successfully from HMDS so a trial is useful before the technique is decided upon as a standard procedure [27, 69]. This technique has been proven to work with most biological sample types, it is easy and it negates the need for expensive and time consuming CPD equipment.

Table 4. Liquid-vapor Critical Temperature and Pressure for Selected Substances [61, 62]

\begin{tabular}{ccc}
\hline Substance & Critical temperature & Critical pressure (absolute) \\
\hline Gold & $6,977^{\circ} \mathrm{C}(7,250 \mathrm{~K})$ & $5,000 \mathrm{~atm}(510,000 \mathrm{kPa})$ \\
Water & $373.946{ }^{\circ} \mathrm{C}(647.096 \mathrm{~K})$ & $217.7 \mathrm{~atm}(22.06 \mathrm{MPa})$ \\
Sulfur & $1,040.85^{\circ} \mathrm{C}(1,314.00 \mathrm{~K})$ & $207 \mathrm{~atm}(21,000 \mathrm{kPa})$ \\
Ammonia & $132.4{ }^{\circ} \mathrm{C}(405.5 \mathrm{~K})$ & $111.3 \mathrm{~atm}(11,280 \mathrm{kPa})$ \\
Chlorine & $143.8^{\circ} \mathrm{C}(416.9 \mathrm{~K})$ & $76.0 \mathrm{~atm}(7,700 \mathrm{kPa})$ \\
$\mathrm{Co}_{2}$ & $31.04{ }^{\circ} \mathrm{C}(304.19 \mathrm{~K})$ & $72.8 \mathrm{~atm}(7,380 \mathrm{kPa})$ \\
$\mathrm{N}_{2} \mathrm{O}$ & $36.4{ }^{\circ} \mathrm{C}(309.5 \mathrm{~K})$ & $71.5 \mathrm{~atm}(7,240 \mathrm{kPa})$ \\
Ethanol & $241{ }^{\circ} \mathrm{C}(514 \mathrm{~K})$ & $62.18 \mathrm{~atm}(6,300 \mathrm{kPa})$ \\
Fluorine & $-128.85^{\circ} \mathrm{C}(144.30 \mathrm{~K})$ & $51.5 \mathrm{~atm}(5,220 \mathrm{kPa})$ \\
Oxygen & $-118.6{ }^{\circ} \mathrm{C}(154.6 \mathrm{~K})$ & $49.8 \mathrm{~atm}(5,050 \mathrm{kPa})$ \\
Nitrogen & $-146.9{ }^{\circ} \mathrm{C}(126.2 \mathrm{~K})$ & $33.5 \mathrm{~atm}(3,390 \mathrm{kPa})$ \\
$\mathrm{CH}_{4}$ (methane $)$ & $-82 .{ }^{\circ} \mathrm{C}(190.8 \mathrm{~K})$ & $45.79 \mathrm{~atm}(4,640 \mathrm{kPa})$ \\
Hydrogen & $-239.95^{\circ} \mathrm{C}(33.20 \mathrm{~K})$ & $12.8 \mathrm{~atm}(1,300 \mathrm{kPa})$ \\
Helium & $-267.96{ }^{\circ} \mathrm{C}(5.19 \mathrm{~K})$ & $2.24 \mathrm{~atm}(227 \mathrm{kPa})$ \\
\hline
\end{tabular}


The procedure is simple:

1. Transfer your sample from $100 \%$ ethanol into a 1:2 solution of HMDS: $100 \%$ ethanol and leave for 20 minutes.

2. Transfer your sample to a fresh solution of 2:1 HMDS: ethanol for 20 minutes.

3. Now transfer the sample into $100 \%$ HMDS for 20 minutes, and repeat this step.

4. When the sample is submerged in the final $100 \%$ HMDS solution leaves covered or capped loosely in a fume hood overnight.

5. All HMDS steps need to be carried out in the fume hood wearing the necessary personal protective gear as it is highly toxic.

6. The HMDS will evaporate, leaving your sample ready for sputter coating and imaging in the SEM.

On a note of safety, HMDS vapor should not be breathed in and any solution mixed with ethanol should not be stored in a closed bottle as vapor pressure can build up and cause an explosion.

In summary, CPD was a time consuming process with low sample reproducibility due to the many manual operations required, whereas HMDS-drying-method proved to be an economical alternative to the CPD method [70]. The capability of HMDS and TMS as a solute for the last step in the dehydration of biological material for scanning electron microscopy was tested. Both the HMDS and TMS drying techniques require sample fixation followed by dehydration. After the final dehydration step, the dehydration agent is replaced with the drying agent, which is then allowed to evaporate at room temperature (HMDS) or 27-32 (TMS) before the specimen is mounted. TMS [54], Peldri IITM [45], a proprietary fluorocarbon, was easy to use and gave good results [44], but is no longer available because of regulations imposed by the U.S. Environmental Protection Agency [27].

\subsection{Mounting Biological Samples}

Samples must be mounted onto holders for the specific SEM being used. Most specimen mounts are made of aluminum or brass, though the brass is more expensive than aluminum and confers no added advantage.
Particulate samples are best attached to poly-L-lysine coated coverslips [71], which are, in turn, attached to stubs. Specimens or coverslips with adherent material may be attached to stubs with colloidal silver paint, colloidal silver paste, colloidal carbon paint, carbon tape, or double-stick tape. If double stick tape is used, some conductive paint or paste must be bridge from the stub to the surface of the specimen, since the tape is an insulator. Coverslips are also insulators, so they must be treated in the same fashion. The various pastes and paints must be allowed to dry before being introduced into the specimen chamber of conventional high-vacuum SEM, otherwise outgassing of the vehicle for the conductive materials will prevent development of adequate vacuum [27].

\subsection{Sputter coating or surface conductivity}

There are two primary purposes for coating samples:

1. To make the samples electrically conductive so that excess electrons trapped by the atoms of the sample can be drawn off to ground, and

2. To introduce contrast to render them visible in the microscope.

As previously noted, biological tissues are generally good insulators and results in imaging artifacts caused by charging in SEM. Once samples are dried, they should be mounted on specimen stubs, coated and examined as quickly as possible. If the samples must store, they should be put in chambers with Drierite ${ }^{\circledR}$ to minimize rehydration from atmospheric humidity. In particular, a coated specimen is subjected to decreased image quality if the specimen swells hygroscopically and develops hairline fracture in the thin metal coating sputtered onto it to increase conductivity.

In conventional high-vacuum SEMs, the primary electron beam current will have no way to reach ground potential, so if the net specimen current is not conducted to ground, image distortion results because the specimen builds up a negative charge from the beam, and the beam repelled by the negative specimen charge. Specimen burning can be a problem in regions that produce charging, as just 
described.

Except carbon, electrically conducting layer for samples to be viewed by SEM, STEM, TEM, the materials to produce coats for biological microscopy are heavy metals. Heavy metals are used to provide both electrical conductivity and a source of secondary electrons for SEM. Application of a nanometer thin layer of heavy metals allows electrons to escape from the sample and go to the ground, without noticeably affecting the surface properties of the sample [4]. Applying an electron dense metal layer to samples composed predominately of light elements such as carbon and nitrogen also helps enhance the return signal off light element specimens, providing greater contrast and surface detail. Biological specimens in SEM are usually coated with platinum, gold or gold-palladium because the fine grain size necessary for conventional SEMs. There are three considerations to take into account when interpreting high resolution images of metal-coated specimens:

1. The thickness of the metal-coat,

2. Its uniformity, and

3. Its granularity.

All coats add material to the surfaces of the sample, making the structures thicker and causing them to appear larger in the microscope. If sufficiently thick, the coat will obscure the sub-structure of the underlying sample. Therefore, it is critical for high resolution work to measure the amount of metal deposited, and to use as thin a coat as possible to accomplish the intended task. The importance of the uniformity with which the coating material is deposited on the specimen varies with the microscopic method. In SEM a uniform coat is essential to prevent electrical charging. The principal problem with metal coating is that the coat may have its own granular sub-structure that will be visualized in high resolution images. In some cases, the granularity of the coat may enhance the surface details of the sample, whereas in other cases, the granularity of the coat may obscure the underlying structures or creat artificial ones. Therefore, when working at high resolution, the granularity of the coat must be taken in to consideration when interpreting the images [4]. All metallic coatings have the disadvantage of producing granular coats in which islands of metal grow together to form a uniform coating only when the coating has become relatively thick $[8,72-$ 75]. For high resolution SEM, it is critical that the metal coat be as thin and grain-free as possible, so that the underlying macromolecular structure is not obscured. Therefore, we have promoted the use of refractory metals such as tungsten, tantalum, and niobium; because they produce coats that are very fine-grained to virtually grain free. This allows the metals to be deposited in very thin continuous layers $(0.5-2 \mathrm{~nm})$ that are electrically conductive and provide adequate numbers of secondary electrons for SEM [8, 38, 72-74, 76].

In the early days of SEM, vacuum evaporators were used to coat specimens. Since vacuum evaporators are directional coater, specimens were placed on motorized holder within the vacuum system in order to coat surfaces of variable topography evenly. These holders spun a disc containing the specimens to go up and down in a clockwise direction while being rotated away from and toward the source. This procedure frequently heated the specimen to an unacceptable level while not producing a truly even metal coating on specimens with much topography. The main disadvantages of evaporative coating are that only metals with relatively low boiling temperatures may be used, and these metals form coatings that have a relatively large grain size. Such metal coats are unsuitable when the goal is to visualize structures at the macromolecular level without decoration artifacts [4].

Sputter-coating was introduced into biological microscopy as an alternative to evaporative coating for SEM [76, 77]. Sputter coaters were introduced to solve these problems. The earliest units still heated the specimens, but the ion cloud of argon and metal atoms dislodged to coat the specimen produced well-coated surfaces for any topography. Sputter coating is done at relatively low vacuum in the presence of an inert gas such as argon, the atoms are scattered at all possible angles as a result of collisions with the gas atom. This produces metal films that are more uniform in thickness than restively evaporated coats. The primary source of damage during sputter coating sample due to presence of electrons in the argon 
plasma that is formed around the sputtering head. This problem can be reduced or eliminated through the use of magnetron sputtering heads, which use a magnetic field to deflect the electrons from the sample [78]. Alternative methods for depositing fine-grained metal films on biological samples are ion beam sputtering [74, 79] and penning sputtering $[73,80]$, in which the sample is placed outside of the charged plasma [4]. In summary, sputter coating also increases the SE signal (and therefore contrast). High $Z$ elements have a higher yield of SEs than low Z elements (biological material).

\section{Conclusion}

In SEM each step required to process a sample for microscopic examination can alter its native structure and create new structures that will be observed microscopically. However, when one has begun to use the SEM instrument, he cannot always take satisfactory photos. When the photo is not sharp enough, or when necessary information cannot be obtained, it is necessary to think what causes it. Some of the routine complications in SEM imaging, especially for biological samples are surface charging, evaporation and dissolving of samples. In hence, technical methods to prepare biological samples should be taken into consideration.

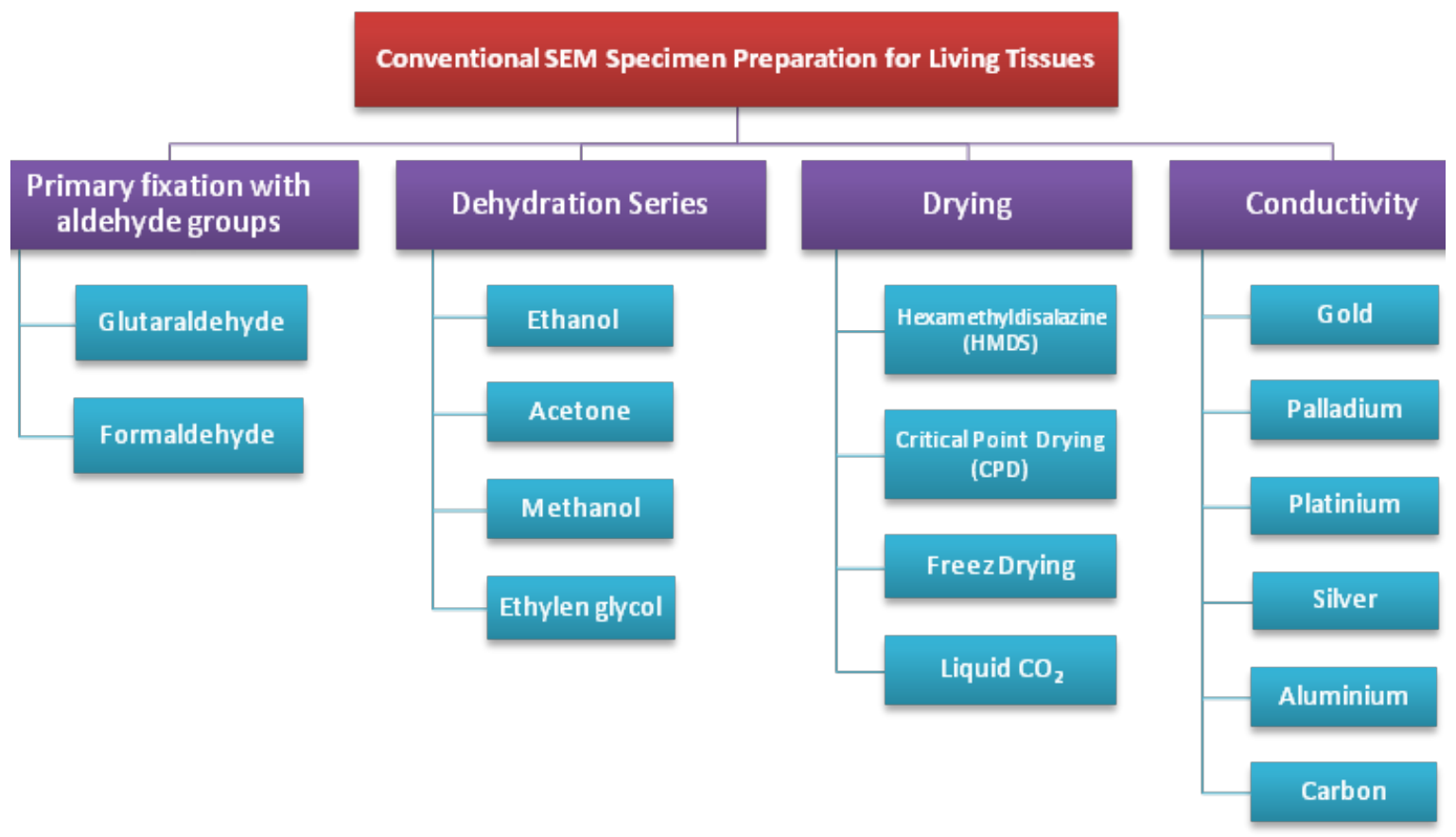

Diagram 1. Suggested Operational Flowchart to Prepare Living Tissues for SEM Characterization. 


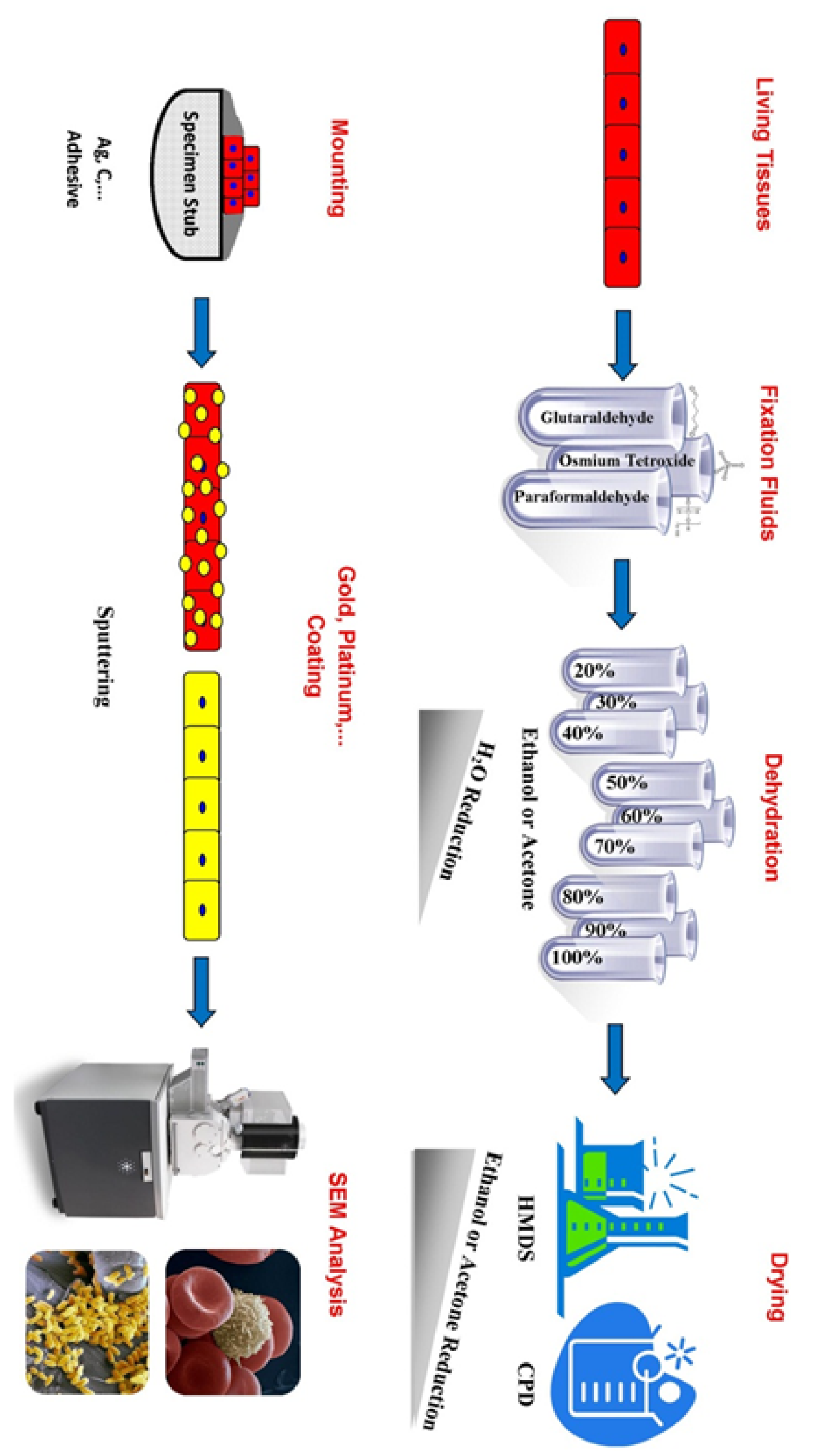

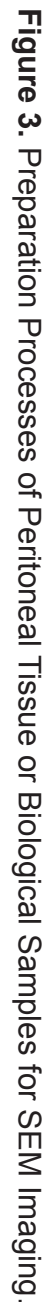




\section{References}

1. Echlin P. Handbook of Sample Preparation for Scanning Electron Microscopy and X-Ray Microanalysis. UK: Springer; 2009.

2. Alberts A, Johnson J, Lewis J, Raff M, Roberts k, Walter P. Molecular Biology of the Cell. 5th ed. 2007.

3. Frieden E. The Chemical Elements of Life. Scientific American. 1972:52-60.

4. Bell PB, Safiejko-Mroczka B. Preparing whole mounts of biological specimens for imaging macromolecular structures by light and electron microscopy. Intl J Imag Sys Tech. 1997;8(3):225-39.

5. Egerton RF, Li P, Malac M. Radiation damage in the TEM and SEM. Micron. 2004;35(6):399-409.

6. Bahr GF, Bloom G, Friberg U. Volume changes of tissues in physiological fluids during fixation in osmium tetroxide or formaldehyde and during subsequent treatment. Exper Cell Res. 1957;12(2):34255.

7. Baker JR. Principles of biological microtechnique; a study of fixation and dyeing: London Methuen; New York, Wiley; 1958.

8. Lindroth M, Bell PB, Fredriksson BA, Liu XD. Preservation and visualization of molecular structure in detergent-extracted whole mounts of cultured cells. Microsc Res Tech. 1992;22(2):130-50.

9. Boyde A. Do's and don'ts in biological specimen preparation for the SEM. SEM/ IITRI. 1976;9:683-90.

10. Bell PB, Revel JP. Scanning electron microscope application to cells and tissue in culture. London: G. M. Hodges and R. C. Hallowes, Academic Press; 1980.

11. Hayat MA. Fixation for electron microscopy: Academic Press, New York; 1981.

12. Hayat MA. Electron microscopy: Biological applications. 4th ed: Cambridge University Press, New York; 2000.

13. Glauert AM, Lewis PR. Biological Specimen Preparation for Transmission Electron Microscopy. A.M. G, editor. New Jeresy: Portland Press, C0-Published by Princeton University Press; 1998.

14. Hopwood D. Fixatives and fixation: a review. Histochem J. 1969;1(4):323-60.
15. Fox CH, Johnson FB, Whiting J, Roller PP. Formaldehyde fixation. J Histochem Cytochem. 1985;33(8):845-53.

16. Bell PB, Rundquist I, Svensson I, Collins VP. Formaldehyde sensitivity of a GFAP epitope, removed by extraction of the cytoskeleton with high salt. J Histochem Cytochem. 1987;35(12):1375-80.

17. Brunk U, Bell PB, Collins VP, Forsby N. SEM of cells in culture: Osmotic effects during fixation. SEM/IITRI. 1975;8:37986.

18. Arborgh B, Bell P, Brunk U, Collins VP. The osmotic effect of glutaraldehyde during fixation. A transmission electron microscopy, scanning electron microscopy and cytochemical study. J Ultrastruct Res. 1976;56(3):339-50.

19. Anderson PJ. Purification And Quantitation Of Glutaraldehyde And Its Effect On Several Enzyme Activities In Skeletal Muscle. J Histochem Cytochem. 1967;15(11):652-61.

20. Torack RM. The extracellular space of rat brain following perfusion fixation with glutaraldehyde and hydroxyadipaldehyde. Zeitschrift für Zellforschung. 1965;66(3):352-64.

21. Hayat MA. Glutaraldehyde: Role in electron microscopy. Micron and Microscopica Acta. 1986;17(2):115-35.

22. Maupin-Szamier P, Pollard TD. Actin filament destruction by osmium tetroxide. J Cell Biol. 1978;77(3):837-52.

23. Lomant AJ, Fairbanks G. Chemical probes of extended biological structures: Synthesis and properties of the cleavable protein cross-linking reagent [35S] dithiobis(succinimidyl propionate). J Mol Biol. 1976;104(1):243-61.

24. Staros JV. N-hydroxysulfosuccinimide active esters: bis(Nhydroxysulfosuccinimide) esters of two dicarboxylic acids are hydrophilic, membrane-impermeant, protein crosslinkers. Biochemistry. 1982;21(17):3950-5.

25. Staros JV. Membrane-impermeant crosslinking reagents: probes of the structure and dynamics of membrane proteins. Account Chem Res. 1988;21(12):435-41. 
26. Mattson G, Conklin E, Desai S, Nielander G, Savage MD, Morgensen S. A practical approach to crosslinking. Mol Biol Rep. 1993;17(3):167-83.

27. Dykstra MJ, Reuss LE. Biological Electron Microscopy: Theory, Techniques, and Troubleshooting. 2nd ed: Springer; 2003.

28. Vanhecke D, Graber W, Studer D. Chapter 21 - Rapidly Excised and Cryofixed Rat Tissue. In: Thomas M-R, editor. Methods in Cell Biology: Academic Press; 2010. p. 513-27.

29. Dalen H, Lieberman M, LeFurgey A, Scheie P, Sommer JR. Quick-freezing of cultured cardiac cells in situ with special attention to the mitochondrial ultrastructure. J Microsc. 1992;168(Pt 3):259-73.

30. Dalen H, Scheie P, Nassar R, High T, Scherer B, Taylor I, Wallace NR, Sommer JR. Cryopreservation evaluated with mitochondrial and $\mathrm{Z}$ line ultrastructure in striated muscle. J Microsc. 1992;165(Pt 2):239-54.

31. Fetter RD, Costello MJ. A procedure for obtaining complementary replicas of ultra-rapidly frozen sandwiched samples. J Microsc. 1986;141(Pt 3):277-90.

32. Nicholas JS, David MS. Rapid Freezing, Freeze Fracture, and Deep Etching 1st ed: Wiley-Liss; 1995.

33. Schwabe KG, Terracio L. Ultrastructural and thermocouple evaluation of rapid freezing techniques. Cryobiology. 1980;17(6):571-84.

34. Gilkey JC, Staehelin LA. Advances in ultrarapid freezing for the preservation of cellular ultrastructure. J Electron Microsc Tech. 1986;3(2):177-210.

35. Sabatini DD, Bensch K, Barrnett RJ. CYTOCHEMISTRY AND ELECTRON MICROSCOPY: The Preservation of Cellular Ultrastructure and Enzymatic Activity by Aldehyde Fixation. J Cell Biol. 1963;17(1):19-58.

36. Bone Q, Denton EJ. THE OSMOTIC EFFECTS OF ELECTRON MICROSCOPE FIXATIVES. J Cell Biol. 1971;49(3):571-81.

37. Brunk U, Ericsson JE. The demonstration of acid phosphatase in in vitro cultured tissue cells. Studies on the significance of fixation, tonicity and permeability.
In: Stoward PJ, editor. Fixation in Histochemistry: Springer US; 1973. p. 121-35.

38. Bell PB, Lindroth M, Fredriksson BA. Comparison of the effects of critical pointdrying and freeze-drying on cytoskeletons and microtubules. J Microsc. 1988;151(Pt 2):103-14.

39. Boyde A, Bailey E, Jones SJ, Tamarin A. Dimensional changes during specimen preparation for scanning electron microscopy. SEM/IITRI. 1977;10:507-18.

40. Fazel Anvari-Yazdi A, Talaei-Khozani T, Yazdani A, Anarkoli AO, editors. Morphological and Viability Study of WJStem Cells on Different Nano-Bioactive Ceramics for Bone Tissue Engineering Application. The 2nd international and the 7 th joint conference of iranian metallurgical engineering and iranian foundrymen societies; 2013; Semnan, Iran: Hamayeshnegar.

41. Fazel Anvari-Yazdi A, Talaei T, Yazdani

A. The biocompatibility study of bio-inert and bio-active ceramics to Wharton's jelly mesenchymal stem cells. Artificial Organs. 2013;37(7):A27-A50.

42. Fazel Anvari-Yazdi A, Yazdani A, Talaei T, Kalantar M. Extraction and Viability Checking of Various Carbonated Hydroxyapatite by Wharton's Jelly Mesenchymal Stem Cell. Sci Intl. 2013;1(5):132-8.

43. Moradi F, Bahktiari M, Joghataei MT, Nobakht M, Soleimani M, Hasanzadeh G, Fallah A, Zarbakhsh S, Hejazian LB, Shirmohammadi M, Maleki F. BD PuraMatrix peptide hydrogel as a culture system for human fetal Schwann cells in spinal cord regeneration. J Neuro Res. 2012;90(12):2335-48.

44. Kan FW. Use of Peldri II as a sublimation dehydrant in place of critical-point drying in fracture-label cytochemistry and in backscattered electron imaging fracture-label. J Electron Microsc Tech. 1990;14(1):21-31.

45. Kennedy JR, Williams RW, Gray JP. Use of Peldri II (a fluorocarbon solid at room temperature) as an alternative to critical point drying for biological tissues. J Electron Microsc Tech. 1989;11(2):117-25. 46. Araujo JC, Téran FC, Oliveira RA, Nour 
EA, Montenegro MA, Campos JR, et al. Comparison of hexamethyldisilazane and critical point drying treatments for SEM analysis of anaerobic biofilms and granular sludge. J Electron Microsc (Tokyo). 2003;52(4):429-33.

47. Dekker NP, Lammel CJ, Brooks GF. Scanning electron microscopy of piliated Neisseria gonorrhoeae processed with hexamethyldisilazane. J Electron Microsc Tech. 1991;19(4):461-7.

48. Forge A, Nevill G, Zajic G, Wright A. Scanning electron microscopy of the mammalian organ of Corti: assessment of preparative procedures. Scanning Microsc. 1992;6(2):521-34.

49. Hazrin-Chong NH, Manefield M. An alternative SEM drying method using hexamethyldisilazane (HMDS) for microbial cell attachment studies on subbituminous coal. J Microbiol Methods. 2012;90(2):96-9.

50. Hochberg R, Litvaitis MK. Hexamethyldisilazane for scanning electron microscopy of Gastrotricha. Bitech Histochem. 2000;75(1):41-4.

51. Lee JT, Chow KL. SEM sample preparation for cells on 3D scaffolds by freeze-drying and HMDS. Scanning. 2012;34(1):12-25.

52. Ting-Beall HP, Zhelev DV, Hochmuth RM. Comparison of different drying procedures for scanning electron microscopy using human leukocytes. Microsc Res Tech. 1995;32(4):357-61.

53. Waterman RE. Preparation of embryonic tissues for SEM. Scan Electron Microsc. 1980(Pt 2):21-44.

54. Dey S, Baul TSB, Roy B, Dey D. A new rapid method of air-drying for scanning electron microscopy using tetramethylsilane. Journal of Microscopy. 1989;156(2):259-61.

55. Dey S. A new rapid air-drying technique for scanning electron microscopy using tetramethylsilane: application to mammalian tissue. Cytobios. 1993;73(292):17-23.

56. Hayat MA. Introduction to Biological Scanning Electron Microscopy: University Park Press; 1978.

57. Reville WJ, Cotter MP. An evaluation of the usefulness of air-drying biological samples from tetramethylsilane in preparation for scanning electron microscopy. J Electron Microsc (Tokyo). 1991;40(3):198-202.

58. Bartlett AA, Burysten HP. A review of the physics of critical point drying SEM/IITRI. 1975;8:305-16.

59. Cohen AL. A critical look at critical point drying theory, practice and artefacts. SEM/ IITRI. 1977;10:525-35.

60. Boyde A, Franc F, Maconnachie E. Measurements of critical point shrinkage of glutaraldehyde fixed mouse liver. Scanning. 1981;4(2):69-82.

61. Emsley J. The Elements (Oxford Chemistry Guides). 3rd ed: Oxford University Press; 1998.

62. Cengel YA, Boles MA. Thermodynamics: An Engineering Approach. 4th ed: McGraw-Hill; 2002.

63. Boyde A, MacOnnachie E. Volume changes during preparation of mouse embryonic tissue for scanning electron microscopy. Scanning. 1979;2(3):149-63.

64. Lindroth M, Bell PB, Fredriksson BA. Comparison of the effects of critical point-drying and freeze-drying on cytoskeletons and microtubules. J Microsc. 1988;151(2):103-14.

65. Bray DF, Bagu J, Koegler P. Comparision of hexamethyldisalazine (HMDS), Peldri II and critical-point drying methods for scanning electron microscopy of biological specimens. Microsc Res Tech. 1993;26(6):489-95.

66. Braet F, De Zanger R, Wisse E. Drying cells for SEM, AFM and TEM by hexamethyldisilazane: a study on hepatic endothelial cells. J Microsc. 1997;186(Pt 1):84-7.

67. Nation JL. A new method using hexamethyldisilazane for preparation of soft insect tissues for scanning electron microscopy. Stain Technol. 1983;58(6):347-51.

68. Ubero-Pascal N, Fortuño JM, de Los Ángeles Puig M. New application of air-drying techniques for studying Ephemeroptera and Plecoptera eggs by scanning electron microscopy. Microsc Res Tech. 2005;68(5):264-71.

69. Perdigao J, Lambrechts P, Van Meerbeek B, Vanherle G, Lopes AL. Field emission 
SEM comparison of four postfixation drying techniques for human dentin. $\mathrm{J}$ Biomed Mater Res. 1995;29(9):1111-20.

70. Kühnel T, Köveker G, Müller GH. Drying with hexamethyldisilizane--a timesaving alternative to the "critical point" method. Handchir Mikrochir Plast Chir. 1989;21(3):164-5.

71. Mazia D, Schatten G, Sale W. Adhesion of cells to surfaces coated with polylysine. Applications to electron microscopy. J Cell Biol. 1975;66(1):198-200.

72. Bell PB, Lindroth M, Fredriksson BA, Liu XD. Problems associated with the preparation of whole mounts of cytoskeletons for high resolution electron microscopy. Scanning Microsc Suppl. 1989;3:117-34.

73. Peters KR. Metal Deposition by HighEnergy Sputtering for High Magnification Electron Microscopy. In: Koehler J, editor. Advanced Techniques in Biological Electron Microscopy III: Springer Berlin Heidelberg; 1986. p. 101-66.

74. Lindroth M, Sundgren JE. Ion beamsputtered and magnetron-sputtered thin films on cytoskeletons: A high-resolution tem study. Scanning. 1989;11(5):243-54.

75. Brunk U, Collins VP, Arro E. The fixation, dehydration, drying and coating of cultured cells for SEM. J Microsc. 1981;123(2):121-31.

76. Bell PB, Lindroth M, Fredriksson B-A. Use of sputter coating to prepare whole mounts of cytoskeletons for transmission and high-resolution scanning and scanning transmission electron microscopy. J Electron Microsc Tech. 1987;7(3):149-59.

77. Echlin P, Gee W, . Very low voltage sputter coating. J Microsc. 1985;137(2):155-69.

78. Nockolds CE, Moran K, Dobson E, Phillips A. Design and operation of a high efficiency magnetron sputter coater. Scan Electron Microsc. 1982;3:907-15.

79. Kemmenoe BH, Bullock GR. Structure analysis of sputter-coated and ion-beam sputter-coated films: a comparative study. J Microsc. 1983;132(2):153-63.

80. Peters KR. Penning sputtering of ultra thin metal films for high resolution electron microscopy. J Electron Microsc. 1980:14354. 